\title{
Erratum: My data are your data
}

Vivien Marx

Nat. Biotechnol. 30, 509-511 (2012); doi:10.1038/nbt.2243; published online 7 June 2012; corrected after print 7 December 2012

In the version of this article initially published, the statement on p. 509, column 2, top paragraph, was missing a few words, making it a fragment: "Besides the risk of duplicating research discoveries that would be missed if data and methods aren't shared," should have read, "Besides the risk of duplicating research, 'it's also about discoveries and breakthroughs that would be entirely missed if data and methods aren't shared'..." On p. 511, column 2, paragraph 3, it was stated that the Lung Genomics Research Consortium (LGRC) shares data within the consortium but not with a wider community. In fact, that is not the case, and the sentence now reads, "Although the LGRC research portal is open, it does not offer sequence-based data, which must go to the NIH database of Genotypes and Phenotypes, where controlled data access policies are in place and individuals are de-identified." Also on p. 511, in column 3, paragraph 2, the European Systems Biology of Microorganisms program was incorrectly identified as SysMo-SEEK. It is SysMo. SysMO-Seek is a data-sharing platform developed for the 13 consortia that make up SysMo. The sentence now reads, "When developing a data-sharing platform called SysMO-SEEK for the European Systems Biology of Microorganisms program.... The errors have been corrected in the PDF and HTML versions of this article.

\section{Erratum: Beyond counting tumor cells}

Jim Kling

Nat. Biotechnol. 30, 578-580 (2012); doi:10.1038/nbt.2295; published online 9 July 2012; corrected after print 7 December 2012

In the version of this article originally published, On-Q-Ity platform was called by its previous and outdated name, C5 (Circulating Cancer and Characterization Chip). It should have been called OnQChip. The error has been corrected in the HMTL and PDF versions of the article.

\section{Erratum: Antibody specification beyond the target: claiming a later- generation therapeutic antibody by its target epitope}

Colin G Sandercock \& Ulrich Storz

Nat. Biotechnol. 30, 615-618 (2012); doi:10.1038/nbt.2291; published online 9 July 2012; corrected after print 7 December 2012

In the version of this article initially published, in Table 1 "Patents claiming anti-TNFa antibodies," patent US 7012135 should have been assigned to UCB Pharma and not UC Berkeley. The error has been corrected in the PDF and HTML versions of this article.

\section{Erratum: Drug pipeline: Q212}

\section{Laura DeFrancesco}

Nat. Biotechnol. 30, 817 (2012); doi:10.1038/nbt.2359; published online 10 September 2012; corrected after print 7 December 2012

In the version of this article initially published, the Thrombogenics drug Jetrea (recombinant microplasmin) was listed in "Notable upcoming regulatory decisions" as indicated for thyroid cancer. It should have read vitreomacular adhesion. The error has been corrected in the HMTL and PDF versions of the article.

\section{Corrigendum: Pharmacogenomics in clinical practice and drug development}

Andrew R Harper \& Eric J Topol

Nat. Biotechnol. 30, 1117-1124 (2012); doi:10.1038/nbt.2424; published online 8 November 2012; corrected after print 7 December 2012

In the version of this article initially published, the funders were not acknowledged. The funding statement should have read "E.J.T. was funded by the National Institutes of Health/National Center for Advancing Translational Sciences TR000109.” The error has been corrected in the HTML and PDF versions of the article. 